\section{NOVA TELLVS}

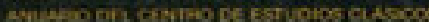

Nova Tellus

ISSN: 0185-3058

novatelu@servidor.unam.mx

Centro de Estudios Clásicos

México

GARCÍA PÉREZ, David

Prometeo: tradición y progreso

Nova Tellus, vol. 24, núm. 2, 2006, pp. 77-109

Centro de Estudios Clásicos

Distrito Federal, México

Disponible en: http://www.redalyc.org/articulo.oa?id=59120913004

- Cómo citar el artículo

- Número completo

- Más información del artículo

- Página de la revista en redalyc.org

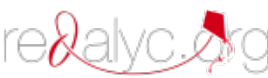

Sistema de Información Científica

Red de Revistas Científicas de América Latina, el Caribe, España y Portugal

Proyecto académico sin fines de lucro, desarrollado bajo la iniciativa de acceso abierto 


\title{
Prometeo: tradición y progreso
}

\author{
David GarCía Pérez \\ Universidad Nacional Autónoma de México \\ prometeo9@att.net.mx
}

Resumen: En este trabajo se analiza el mito de Prometeo en las versiones de los poemas de Hesíodo (Teogonía y Los trabajos y los días) y de la tragedia Prometeo encadenado, pieza atribuida a Esquilo. Con la comparación de tales relatos, se busca explicar los conceptos de tradición y progreso, de acuerdo con el contexto en que se produjeron los materiales literarios aludidos.

$$
* * *
$$

ABSTRACT: This paper analyses the myth of Prometheus according to the Hesiodic poems (Theogony and Works and Days) and Prometheus Bound, a tragedy attributed to Aeschylus. By comparison, the aim is to explain the concept of tradition and progress on the basis of the context that this literature was made.

Palabras clave: Esquilo, Hesíodo, Los trabajos y los días, mito, progreso, Prometeo, Teogonía, tragedia griega.

RECEPCIÓn: 18 de agosto de 2006.

ACEPTACIÓN: 3 de octubre de 2006. 



\title{
Prometeo: tradición y progreso
}

\author{
David García PÉREZ
}

\begin{abstract}
Le long silence de Prométhée devant les forces qui l'accablent crie toujours. Mais Prométhée a vu, entretemps, les hommes se tourner aussi contre lui et le railler. Coincé entre le mal humain et le destin, la terreur et l'arbitraire, il ne lui reste que sa force de révolte por sauver du meurtre ce qui peut l'être encore, sans céder à l'orgueil du blasphème.

Albert Camus, L'homme révolté
\end{abstract}

De acuerdo con la configuración tradicional de los personajes literarios, atendiendo el aspecto del mito, hallamos, en la literatura griega antigua, tres modelos: dios, héroe y hombre. ${ }^{1}$ Los extremos señalados por el dios y el hombre, en general, tienen sus características mucho más delimitadas en comparación con el héroe. Por tal razón, éste se puede definir como un ser en tránsito, en movimiento constante, cuyo objetivo es separarse del común de los mortales y hacer el camino hacia lo divino. De aquí que también se comprenda por qué el héroe posee cualidades físicas, éticas, estéticas y epistémicas que pronto lo colocan por arriba del resto de los mortales.

Ahora bien, en la cultura griega antigua, hay un rasgo común en los héroes que explica el movimiento señalado: el sentido de lo trágico. Al situarse en medio de dios y del hombre, el estado del héroe es el del sufrimiento incesante, porque no se limita a ser un simple mortal, pero tampoco puede alcanzar la perenni-

\footnotetext{
${ }^{1}$ Cfr. Hom., Il., XII, 22; Hes., Erga, v. 159; Pind., Olimp., II, 1.
} 
dad y, a veces, también rechaza abiertamente esa condición, como es el caso de Aquiles cuando se halla en el infierno. ${ }^{2}$

Afirma Camus, en L'homme révolté, que el ser humano es el único animal que no se conforma con lo que es. ${ }^{3}$ Tal situación aleja al hombre de la esfera divina, al punto de que éste decreta la muerte de dios y, al mismo tiempo, marca distancia de lo que convencionalmente se define como humano. En efecto, la inconformidad es lo que el héroe manifiesta como tragedia y lo que lo impele a proponer y a llevar a cabo empresas que están fuera de su alcance. Cuando Ismene rechaza el plan de su hermana Antígona y se niega a participar en la inhumación de Polinices en contra de la voluntad del tirano, Creonte, la razón que ella esgrime es precisamente la que denota el carácter de quien renuncia a la heroicidad: no se puede hacer nada más allá de lo que humanamente es posible. El héroe, entonces, es aquel que de modo consciente sabe que el destino le es contrario en todo sentido, pero aun así se encamina hacia los brazos de la desgracia, pues quiere alcanzar su objetivo, o bien, no tiene otra opción más que continuar con el desarrollo de su vida.

Además, para que el héroe crezca ante los ojos del espectador es necesario que exista su contraparte. El antagonista marca la pauta para que el héroe despliegue todas sus herramientas a fin de que le sea posible alcanzar su meta, aunque de antemano sabe que es punto menos que imposible: el principal obstáculo del héroe es su propio destino, el cual cobra cuerpo en algún personaje que funciona como un mero instrumento.

La heroicidad depende también del momento histórico. Las condiciones del contexto son esenciales para definir lo que es heroico. Cuando tales condiciones responden de modo más o menos uniforme con la figura del héroe a tratar, cabe hablar

${ }^{2}$ Hom., Od., XI, 487-491.

${ }^{3}$ A. Camus, L’homme révolté, p. 24. 
entonces del llamado héroe cultural. Bajo los postulados delimitados por la tragedia y por el desarrollo cultural es como se puede analizar el mito de Prometeo, un personaje cuya complejidad hace que se haya visto tanto como símbolo del atraso como del progreso, en su sentido más amplio.

En la cultura griega, la figura de un dios redentor de los hombres, con características de héroe, aparece descrita por primera vez en el mito prometeico; y de éste, la versión más antigua que se conoce por escrito, sin perder de vista su cercana y fuerte reminiscencia oral, es la elaborada por Hesíodo en dos pasajes de sus poemas épicos: en la Teogonía, vv. 507616, y en Los trabajos y los días, vv. 43-105. No obstante, para el poeta beocio, el Titán de ningún modo es un héroe, todo lo contrario: bajo la idea de Dike (Justicia) que desarrolla en sus dos poemas, Prometeo es enemigo del orden, pues sus acciones resultan contraproducentes para el status quo que pretende Hesíodo. El rango de héroe se lo otorga el autor de Prometeo encadenado, como veremos más adelante, y es esta imagen la que prevalece en las tradiciones literarias de occidente. ${ }^{4}$ Así pues, tenemos dos relatos sobre la significación del mito de Prometeo: el de Hesíodo, que apunta al mantenimiento de cierta tradición mítica-religiosa, y el de Prometeo encadenado, tragedia que está orientada hacia el sentido del progreso. ${ }^{5}$ En ambos casos, es el contexto el que permite determinar una interpretación del mito, puesto que pertenecen a dos momentos históricos distintos: la tiranía para el primero y la democracia para el segundo.

\footnotetext{
${ }^{4}$ Prometeo encadenado ha pasado a la posteridad como obra de Esquilo, pero las argumentaciones en contra de tal paternidad sugieren proceder con cautela. Cfr. S. Saï, Sophiste et tyran, pp. 9-12.

5 Discrepamos de la interpretación de F. Solmsen, Hesiod and Aeschylus, p. 154, para quien "Hesiod was the first to understand the world order of his time as the final result of an historical and genealogical process", pues tal planteamiento se halla sobre la base de una comprensión inmersa en el ámbito mítico y religioso, de tal suerte que la evolución se opera en el tiempo sagrado, ajeno a la evolución socio-histórica que interpretó el autor de Prometeo encadenado.
} 
La época de Hesíodo fue de cambios profundos en el orden socioeconómico, los cuales se vieron reflejados en el pensamiento y en las actitudes morales del pueblo griego. Los poemas hesiódicos fueron, en gran medida, una respuesta a la crisis que vivió Beocia - la tierra natal de Hesíodo-, y en general toda la Grecia del Asia Menor, y también constituyeron una respuesta ética del poeta ante las injusticias que él vivió en carne propia. Tal situación mostraba hasta qué punto las comunidades griegas de entonces necesitaban con urgencia un reacomodo social.

Hesíodo describió con penetrante amargura el ambiente que lo rodeaba. En un solo verso pintó su pueblo natal. "Ascra: en invierno dura, en estío penosa, nunca benigna". ${ }^{6}$ A las adversas condiciones naturales y económicas hay que sumar uno de los problemas que el poeta beocio consideró esenciales: la concepción y aplicación de la Dike. Hesíodo pensaba que la justicia era un don que Zeus otorgó a los hombres, pero éstos la corrompieron. El ejemplo que sustenta tal parecer es evidente: Perses, hermano de Hesíodo, había incoado contra éste un juicio, pues reclamaba, injustamente según se puede colegir de lo dicho por el poeta, parte de la herencia paterna. Hesíodo, ante un segundo juicio que quizá perdió, no dudó en calificar a los jueces como devoradores de bienes. ${ }^{7}$

¿Por qué la sociedad se encontraba en ese estado tan lamentable, según la versión hesiódica? Una respuesta se halla en el mito de Prometeo. En efecto, en los dos poemas de Hesíodo, el elemento prometeico es de capital importancia. A ningún otro relato el poeta beocio le dedicó tantos versos como a éste, pues hay que considerar que bajo él se agrupan otros dos grandes mitos: el de las cinco razas y el de Pandora.

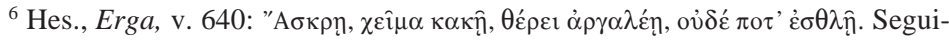
mos la traducción de Paola Vianello de Córdova: Hesíodo, Teogonía, México, Universidad Nacional Autónoma de México, 1986.

${ }^{7}$ Hes., Erga, vv. 27-41.
} 
En suma, el mito de Prometeo es una síntesis de la historia del hombre.

En Los trabajos y los días se encuentra el mito de las cinco razas, ${ }^{8}$ que narra cómo se sucedieron las etapas por las que el hombre ha pasado. El orden en el que el relato presenta cada una de éstas es decreciente, de acuerdo con la actitud que los hombres toman ante la justicia y el cosmos divinos, hasta llegar a la época de Hesíodo, quien vio un futuro incierto y de pesadumbre, si los seres humanos seguían observando una conducta distinta a la sustentada por la justicia de Zeus. Simbólicamente, las razas son denominadas en orden decreciente como raza de oro, plata, bronce, semidioses o héroes y hierro. La raza de hierro es la que corresponde a los tiempos aciagos que vive Hesíodo y, tal vez, es la que se sigue viviendo en nuestros días en muchos aspectos.

El mito de las cinco razas señala claramente que la visión hesiódica sobre el mundo gira alrededor de la justicia; los hombres de hierro están gobernados por Zeus, quien, según Hesíodo, es la Justicia misma que se hace evidente por medio de la diosa Dike, hija del Cronida y de Temis, la ley inmortal. El hierro, como material de poca valía en comparación con el oro, simboliza la atención que el hombre pone a los asuntos de la justicia; por ello se explica la decadencia que el poeta describe.

Ahora bien, esta quinta raza es la que también posee una raíz prometeica. La historia de Deucalión está conectada con el mito prometeico, pues, según la versión hesiódica, este héroe es hijo de Prometeo y de Pandora - otra tradición lo hace descender de Climene, en lugar de Pandora-, que a su vez dio origen, junto con Pirra, al primero de los griegos y fundador de la Hélade: Heleno. Pirra, por su parte, es hija de Epimeteo, hermano de Prometeo, y de Pandora, quienes, en

\footnotetext{
${ }^{8}$ Hes., Erga, vv. 109-201.
} 
efecto, aparecen unidos en Los trabajos y los días. ${ }^{9}$ Deucalión y Pirra fueron los únicos seres sobrevivientes del diluvio que Zeus envió para destruir a los hombres de la Edad de Bronce, quienes ya no seguían la justicia decretada por él.

Deucalión y su esposa pudieron salvarse gracias a que Prometeo les indicó que construyeran un arca y que se introdujeran en ella mientras duraba la inundación. Cuando ésta acabó, Zeus les anunció, por medio de Hermes, que les cumpliría un deseo, y Deucalión pidió que la tierra se poblara. Zeus les dijo, entonces, que arrojaran por encima de sus espaldas los huesos de su madre, y ante esta respuesta Deucalión y Pirra arrojaron piedras sobre sus espaldas y de ellas fueron naciendo los nuevos hombres y mujeres.

Hay varios aspectos que resaltar en torno a este mito. En principio, la raza de los hombres como tales, es decir, fuera de la esfera divina, tiene su origen después del diluvio. Pandora es considerada la primera mujer, pero es una creación divina, a diferencia de Pirra que no tiene las mismas cualidades de sus padres y da origen a una nueva estirpe de mujeres. Lo mismo ocurre, evidentemente, en el caso de Deucalión, salvo que no se sabe quién fue el primer hombre, pues éste debió existir mucho antes del diluvio, incluso su origen se puede remontar a la edad de oro. Este asunto revela en cierto modo la naturaleza del hombre descrita por Hesíodo: las razas humanas se alejan cada vez más de su origen divino por su actitud ante la justicia de Zeus, y esto parece ser un proceso cíclico. La raza de hierro desde siempre no fue bien vista por Zeus. Y, de acuerdo con la versión hesiódica, esto se debe a los engaños con los que Prometeo retó los designios del Cronida: el ardid que aquél comete contra éste en el reparto de las carnes del animal sacrificado y el robo del fuego sagrado.

Las dos faltas cometidas por Prometeo tienen consecuencias inmediatas, pues Zeus decide castigar a este dios y a los

${ }^{9}$ Cfr. Erga, vv. 83 y ss. 
hombres, tal situación se describe en Los trabajos y los días: en primer lugar, se explican las consecuencias nefastas que para el ser humano se dieron a partir de la rivalidad entre Zeus y el Titán; en segundo término, se afirma que uno de los mayores castigos para el género humano fue la creación de la primera mujer, Pandora, y la aceptación de ésta como esposa por parte de Epimeteo, lo cual significa un castigo perenne para los varones; en tercer lugar, se habla del castigo de Zeus contra Prometeo, quien fue encadenado al Cáucaso y condenado a padecer la tortura de un águila que le comería las entrañas, hasta que Heracles lo liberara; por último, se expone la justificación ${ }^{10}$ de la existencia del mal y del trabajo penoso entre los hombres, para obtener el sustento.

Así pues, el tópico en el que se centra la narración hesiódica en torno a Prometeo es el engaño. En los dos relatos de Hesíodo está presente el triunfo de Zeus como respuesta a cada uno de los engaños del Titán: en el primer caso se tiene una explicación del pacto entre hombres y dioses a través del sacrificio que habrían compartido en Mecona, en el cual Prometeo engaña por primera vez a Zeus al darle a elegir una de las dos partes en las que había dividido el buey: en un lado puso la carne y las entrañas envueltas en la piel, de modo que parecía sólo un montón de huesos; y en la otra parte cubrió el esqueleto con abundante grasa para que diera la impresión de que era la carne. El padre de los dioses se dejó engañar, según Hesíodo, pues ya estaba pensando en el castigo futuro y eligió la segunda porción. Así, la respuesta de Zeus a tal afrenta,

\footnotetext{
${ }^{10}$ Se trata de una justificación de la existencia del mal y del trabajo, porque el poeta explica el modo en que los males, ya existentes desde el origen mismo del cosmos (cfr. Theog., vv. 21-233), son introducidos en el género de los hombres por Pandora, tal como Jean-Pierre Vernant en Mito y pensamiento en la Grecia antigua, p. 61, ha interpretado: "Con Pandora, en efecto, no solamente los poderes de la Noche se extienden a través de la Tierra, los Algea de las enfermedades, el Ponos, la Geras, estos males que la humanidad en su pureza original ignoraba, sino que todo bien ahora encierra su contrapartida de mal, su aspecto nocturno, su sombra que le sigue paso a paso".
} 
ocultar el fuego a los hombres, resulta un mito etiológico que perfila el constante peligro de la desaparición del género humano.

El segundo engaño de Prometeo consiste en robar el fuego sagrado que Zeus había escondido y en entregárselo a los hombres, con todas las implicaciones relativas a la civilización que puede tener en sí el símbolo del fuego. Esto último no es motivo de interés en la exposición de Hesíodo, como sí lo será en la versión de Prometeo encadenado. A tal engaño, Zeus contesta con la creación de la primera mujer, Pandora, un bello mal que haría contrapeso a los beneficios del fuego. Sin embargo, en la Teogonía se advierte que la mujer es la productora de las desdichas del hombre, por su propio carácter, mientras que en Los trabajos y los días ella es el instrumento de la venganza de Zeus, al abrir, por orden de éste, la tapa de la jarra que llevaba consigo, de la cual salieron todas las calamidades que azotan a los mortales.

Es posible observar un paralelismo entre los elementos simbólicos que componen esta sección del mito: por un lado, el camuflaje de las partes en que el Titán dividió la carne del sacrificio para engañar a Zeus tiene su correspondiente en el robo del fuego $\mathrm{y}$, por otra, el regalo del fuego prometeico a los hombres se equilibra con el regalo de Pandora, es decir, "la que lleva todos los dones", ${ }^{11}$ lo cual resulta paradójico, pues tales regalos no son más que desgracias para la humanidad. Estas respuestas indican la presencia de una creación mítica relativa a las causas de las desgracias que acompañan y torturan al Titán y de un Zeus omnisapiente, omnipotente y omnividente, dispuesto siempre a que los males se cumplan. ${ }^{12}$

En efecto, de lo anterior se desprende lo siguiente: en primer lugar, la costumbre humana de ofrecer en sacrificio a los dioses los huesos y la grasa, reservándose para sí la mejor

\footnotetext{
${ }^{11}$ Hes., Erga, vv. 80-82, y Theog., v. 588.

${ }^{12}$ Hes., Erga, vv. 229, 267 y 281.
} 
parte de los animales: la carne. Este sacrificio, el cual según la tradición mitológica sería el primero en la cultura griega, ${ }^{13}$ supone que los hombres que asistieron a Mecona para que se definieran las concomitancias entre ellos y los dioses,,${ }^{14}$ conocían el fuego que les será arrebatado por Zeus más tarde, debido al engaño de Prometeo. Si los campesinos de la época de Hesíodo padecen hambre, la culpa puede deberse al engaño que Prometeo hizo en el reparto de las carnes sacrificiales, pues la vida de los hombres que existían bajo el reino de Cronos, al conocer el fuego, tuvo que haber sido más grata. ${ }^{15}$ Sin embargo, hay que resaltar que es Prometeo el encargado de hacer tal sacrificio, es él el intermediario entre los dioses y los hombres y, por lo tanto, él es también el depositario del fuego, al menos en ese momento, que supone un ritual trascendental porque se trata de establecer la relación dios-hombre. ${ }^{16}$

Así, es lícito decir que el mito de Prometeo surge de la tensión por organizar las relaciones en el universo de los dioses y las formas que delimitan lo humano y lo divino. Esta tensión es simbolizada por la figura del Titán, en cuanto que es el lazo que iba del cielo a la tierra y que tenía que expandirse hasta romperse. Se puede leer el mito prometeico en los versos hesiódicos como el momento de ruptura entre los dioses y los hombres, el instante en que la raza humana se separa de las divinidades porque ésta posee el fuego, lo que la convierte, hasta cierto punto, en una afrenta y en un peligro para las mismas divinidades. En la Teogonía y en Los trabajos y los días se describe un mundo en el cual el hombre está inmerso

${ }^{13} \mathrm{Al}$ respecto, cfr. J. L. Durand, "Le rituel du meurtre du boeuf et les mythes du premier sacrifice animal en Attique", en Il mito greco, pp. 121 y ss.

${ }^{14}$ Hes., Theog., vv. 535-537.

${ }^{15}$ Cfr. George Thomson, "Prometheia", en Aeschylus. A Collection of Critical Essays, p. 125; L. Séchan, Le mythe de Prométhée, pp. 26-27.

${ }^{16}$ Carl Kerényi, Prometheus, p. xx: "For the Greeks the story of this sacrifice as told by Hesiod was the statement of a great primordial reality which determined the subsequent existence and fate of mankind". 
de modo integral, pero no es un protagonista, ${ }^{17}$ como sucede en las narraciones homéricas. A partir de lo anterior es lícito conjeturar que la tragedia del héroe rompe la barrera de lo estrictamente individual para diseminarse en el contorno completo del cosmos.

Quizá la ruptura entre el mundo de los dioses y el del hombre se debe a que el sacrificio finalmente no se cumplió, no se llevó a cabo totalmente debido al engaño de Prometeo, de manera que no hay contrato entre los actores de ese ritual y éste tiene que suceder y terminar completamente con el regalo divino de Pandora. ${ }^{18}$

Por lo que toca al tópico del sacrificio hay otro paralelismo simbólico que se relaciona con el vientre: Prometeo envuelve la carne del sacrificio en el gaster del animal sacrificado. Esta imagen sustenta una correspondencia sígnica con el vientre humano, que tiene que llenarse también con todos los alimentos que, en cierta forma, resultan una carga; así, el hombre se convierte en un esclavo de su estómago, de modo que el mismo ser humano corre el riesgo de convertirse en vientre. ${ }^{19}$ Pero si el vientre del hombre es una carga, el de la mujer es muy pernicioso porque además de voraz es lúbrico. ${ }^{20}$ Esto significa que Zeus castigó de esta manera a los hombres: el vientre, como la mujer, es un estigma del cual aquéllos no pueden separarse sin que eso no les signifique la muerte.

\footnotetext{
${ }^{17}$ Paola Vianello, "Introducción”, en Hes., Teogonía, p. LXVIII.

${ }^{18}$ En la mayoría de las culturas existe el sacrificio primigenio que instituye y organiza la conexión entre los dioses y los hombres. Este tipo de ritual es una necesidad cultural y espiritual para que la sociedad pueda avanzar en todos sus componentes; es, a final de cuentas, una especie de pacto como los que cualquier comunidad establece en su seno para dirimir sus problemas y así poder progresar. Y también se vislumbra que siempre hay un intermediario, que es un sacerdote, un chamán o un héroe que adquiere, algunas veces, nombre propio: Abraham, Enki, Prometeo.

${ }^{19}$ Hes., Theog., v. 26: "Pastores agrestes, tristes oprobios, vientres tan sólo". Con tales palabras Zeus se dirige a los hombres.

${ }^{20}$ Hes., Theog., v. 599: "la ajena fatiga en el vientre propio cosechan" (sc. las mujeres). Cfr. el comentario de Jean-Pierre Vernant, op. cit., pp. 41-42.
} 
Ahora bien, además del engaño y de las consecuencias de éste, la idea del fuego es un punto primordial en la historia de Prometeo. En la mayoría de las culturas antiguas el fuego es un elemento central en los ritos y en el desarrollo social: hay dioses del fuego, un lugar sagrado para éste y un tiempo determinado para encender el fuego nuevo. ${ }^{21} \mathrm{El}$ fuego cumple dos funciones básicas: la fecundación de la tierra para una buena producción de alimentos ${ }^{22}$ y la purificación de los cuerpos y, en general, de los objetos que, de acuerdo con los rituales, sean tocados por él. Dentro de la purificación, es posible advertir que el fuego también presenta un rasgo destructor que "abrasa y consume todos los elementos nocivos, materiales o espirituales que amenazan la vida de los hombres, animales y plantas"; 23 en suma, el fuego tiene una virtud positiva y una negativa.

En el mito prometeico están presentes las dos virtudes del fuego: lo positivo está en que el hombre puede cocer sus alimentos y desarrollar las técnicas productivas que le permiten sobrevivir lejos de los dioses y con los castigos impuestos por Zeus; lo negativo está en el castigo encarnado en la mujer; pero también se encuentra en la incapacidad que ésta tenga para conservar, cuidar y manejar el fuego. Así, como Prometeo fue el encargado del fuego en el sacrificio primigenio, esta función le corresponde también al hombre, de aquí en adelante, al haberlo heredado: el ser humano adquiere la responsabilidad de renovar el fuego de manera que no pierda su esencia catártica y propiciatoria. ${ }^{24}$ Como se puede observar, este vínculo de la

\footnotetext{
${ }^{21}$ J. G. Frazer, La rama dorada, pp. 684 y ss.: "En toda Europa, desde tiempo inmemorial, los campesinos han acostumbrado encender hogueras en ciertos días del año y saltar a su alrededor o saltar sobre ellas. [...] Las épocas del año en que por lo regular se encienden estas hogueras son primavera y verano, pero en algunos lugares las encienden también a final de otoño o durante el invierno".

${ }^{22}$ De allí que muchas fiestas relacionadas con el fuego se celebraran en fechas específicas del calendario agrícola, como los solsticios.

${ }^{23}$ J. G. Frazer, op. cit., p. 722.

${ }^{24}$ Cfr. L. Séchan, Le mythe de Prométhée, pp. 2 y 3, y J. G. Frazer, op. cit., pp. 684 y ss., hay un análisis sobre el culto del fuego en las tradiciones folklóricas.
} 
humanidad con lo sagrado tiene su origen, en gran medida, con la cuestión prometeica.

Las consecuencias que padece el hombre por culpa de Prometeo se pueden compendiar en lo siguiente: el fuego es un elemento que conecta, de alguna manera, a los hombres con los dioses, puesto que, para hacer los sacrificios, los hombres necesitan del fuego que es de carácter sagrado. De ahí que, si Zeus hubiera ocultado para siempre el fuego, no habría mortales que alimentaran a los dioses. Desde la perspectiva antropológica, esto significa que se establece una especie de contrato social para que ambas partes puedan sobrevivir, y si esta premisa resulta válida, entonces cabe pensar que la acción de Prometeo no sólo era importante, sino también necesaria, ya que de él se beneficiaron incluso los otros dioses. ${ }^{25}$ Además, como mito etiológico, lo que cuenta Hesíodo conduce a pensar en la búsqueda del equilibrio que permitiría a los actores de este drama encontrar el mejor lugar en las relaciones entre hombres y dioses en la reunión de Mecona.

Ahora bien, como Hesíodo parte de la creencia de que la voluntad de Zeus es inquebrantable, el poeta buscó, a través de esta idea, dejar constancia del orden establecido por éste como dios padre y dueño de todo: "no es posible engañar ni eludir la mente de Zeus", ${ }^{26}$ o como se lee en otra parte: "de ningún modo es posible eludir la mente de Zeus". ${ }^{27}$ Lo que llama la atención es el hecho de que, a pesar de que Prometeo y los hombres fueron castigados, los dioses olímpicos no restituyeron o resarcieron los engaños del Titán; es decir, que los dioses se quedaron con la grasa y los huesos de los sacrificios, mientras que el hombre no pudo deshacerse de su obsequio

\footnotetext{
${ }^{25}$ Luciano de Samosata, en su diálogo Prometeo, argumenta la necesidad de la existencia humana para la vida de los dioses ( $\$ 13-14)$, los cuales no requieren del fuego ( $\S 18-19)$, mientras que la humanidad sí y con él llevan a cabo los sacrificios con los que nutren a las divinidades.

${ }^{26}$ Hes., Theog., v. 613.

${ }^{27}$ Hes., Erga, v. 105.
} 


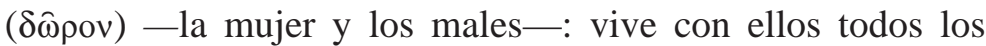
días. Quizá esto sea la expresión de la justicia o del destino determinado por encima de los hombres y de los dioses que hace irrevocable una actitud o acción marcada como la de Prometeo: una vez que él roba el fuego o engaña en el sacrificio a Zeus, las consecuencias son inevitables y forman parte de un plan ya conocido por el Cronida.

En efecto, el cosmos que Hesíodo proyecta tiene como principio normativo superior a la justicia que priva sobre la existencia humana, pues en ella el poeta reconoce un aspecto del orden absoluto que gobierna el universo - la themis-, y cuyas raíces tienen su cimiento, a su vez, en la equidad —el kairós - y en el buen gobierno - la eunomía-. Este aspecto justo y equilibrado del cosmos es roto por Prometeo, quien al desafiar los designios de Zeus obra en el mismo nivel que el de un hybristés. ${ }^{28} \mathrm{Al}$ enmarcar su relato en el mundo sagrado, Hesíodo abolió la rebelión, de tal suerte que la condena a Prometeo es incuestionable. Desde la perspectiva de Camus,

$\mathrm{Si}$, dans le monde sacré, on ne trouve pas le problème de la révolte, c'est qu'en vérité on n'y trouve aucune problématique réelle, toutes les réponses étant données en une fois. La métaphysique es remplacée par le mythe. Il n'y a plus d'interrogations il n'y a que des réponses et des commentaires éternels, qui peuvent alors être métaphysiques. ${ }^{29}$

Si el planteamiento del cosmos se proyecta hacia lo divino, la rebelión se excluye y, al mismo tiempo, se anula el progreso, porque se pretende un status quo atemporal. Así pues, se debe advertir que Hesíodo introduce un elemento transformador

\footnotetext{
${ }^{28}$ Giancarlo Finazzo, La realtá di mondo nella visione cosmogonica esiodea, p. 119: "E che essa stessa (sc. la díke) sia a sua volta fondata sull'equità e sull'equilibrio, é confermato dal fatto che ciò che a lei si contrapone è la üßpıs, ossia la non-misura e quindi il non-equilibrio".

${ }^{29}$ A. Camus, op. cit., p. 36.
} 
dentro del pensamiento griego tradicional al aplicar un criterio ético al material mitológico, lo que apunta a una cierta reforma religiosa. Además, el mito de Prometeo está contado en relación con problemas reales y cotidianos —el mal, el trabajo, la responsabilidad-, a los cuales el poeta da una respuesta de carácter mitológico y moral, y con ello crea "una teología en un sentido muy auténtico, pues nos ofrece una explicación mítica de ciertos hechos morales y sociales comparable con el relato bíblico de la caída". ${ }^{30}$

Si bien es cierto que en Hesíodo se aprecia el pesimismo de un hombre que mira la decadencia en que está hundida su sociedad, también es verdad que en él se advierte la respuesta potencial para remediar, en la medida de lo posible, ese caos: la justicia que se manifiesta en los designios de Zeus. Hesíodo dio un paso muy importante al dilucidar el concepto de justicia en los órdenes divino y humano, pues imprimió un cambio en la concepción ética de Homero sobre los dioses. Las deidades en los poemas homéricos son antropomorfas, piensan y sienten como los humanos. En Homero no hay rastro evidente de una conceptualización ética del plano religioso. Tal vez por eso Hesíodo tuvo la necesidad de pensar el mundo desde otra perspectiva, un mundo con un orden diferente al homérico, que se evidenció al conceder a los dioses un lugar superior en relación con el hombre, de modo que se produjera una vinculación jerárquica bien definida.

Quizá el panorama decadente que Hesíodo observó en su época, le provocó cierta repugnancia por lo humano, al grado de afirmar que debió haber muerto pronto o debió nacer más tarde, ${ }^{31}$ de forma que, entonces, es adecuada con su contexto la manera como presentó el mito prometeico. En efecto, el disgusto que Zeus tiene con los hombres, que manifiesta a través del castigo a Prometeo y a estos mismos, es un indicio

\footnotetext{
${ }^{30}$ Werner Jaeger, La teología de los primeros filósofos griegos, p. 18.
}

${ }^{31}$ Hes., Erga, v. 175. 
de los sentimientos propios del poeta: el desprecio por la forma en que los hombres hacen la justicia es algo que aparece en Hesíodo como una característica que define, en contraparte, el espíritu de Zeus. De este modo, el mito de Prometeo presenta una dilucidación moral de lo que es la justicia divina y su reflejo en los hombres. ${ }^{32}$

Prometeo es un ser ambivalente. Su heroicidad manifiesta dos virtudes, como sucede con el símbolo del fuego: por un lado trata de ayudar a los hombres, con los cuales se identifica y de donde le viene, a partir de la versión atribuida a Esquilo, la imagen de benefactor; y por otro intenta engañar al dios supremo, y ese engaño es para ayudar precisamente al género humano; con todo ello se rebela contra la voluntad del Cronida. La oposición entre Zeus y Prometeo no es sólo de características o de temperamentos: la determinación de estas dos divinidades describe por sí misma el orden que se busca fundar en el pensamiento religioso de los antiguos griegos. La rebeldía encarnada en Prometeo es el reducto de las luchas entre las potencias divinas, mientras que Zeus es la coronación del cosmos iniciado en la cópula de Gea y Urano.

Ahora bien, Prometeo, al defender a los hombres y darles el fuego, también les está otorgando la sabiduría, hecho que Hesíodo soslaya, pues para él el conocimiento correcto pertenece sólo a Zeus. El ser humano no puede progresar sin el conocimiento. El progreso implica necesariamente la inteligencia. El hombre le debe la inteligencia a Prometeo. La luz del fuego lo es también de la sabiduría; pero ésta, como la mujer, es asimismo un mal, una retribución por lo que el hombre puede avanzar.

Hay, sin embargo, manifestaciones de un espíritu irracional en varias actitudes o características culturales de los griegos

\footnotetext{
32 Jean-Pierre Vernant, op. cit., p. 21: "El mito de Prometeo encierra una moral tan clara que no existe para Hesíodo necesidad alguna de explicarla; basta dejar hablar al relato: por la voluntad de Zeus [...], los humanos están obligados desde ahora en adelante al trabajo".
} 
antiguos, sobre todo en el campo religioso, como la cuestión dionisiaca, por ejemplo. Pero no hay que perder de vista que las lecturas de Hesíodo son canónicas en la visión más clásica de la cultura griega. Homero y Hesíodo son quienes determinan, en gran medida, las propiedades de los dioses griegos, y aquellos aspectos míticos y religiosos que no entran en su mundo narrativo son un tanto marginados. En efecto, a pesar de las variaciones en los elementos mitológicos, es posible distinguir en la obra del poeta beocio un modelo de creación tradicional, en el cual sólo aparecen readaptaciones de acuerdo con el sentido de lo que se narra.

El aspecto irracional se aprecia en otro paralelismo interno en el mito prometeico constituido por la aparición de Epimeteo, hermano de Prometeo. La función de este personaje es definir un carácter torpe e incauto para resaltar la inteligencia de Prometeo, o quizá para que se justifique la aceptación del regalo de Zeus para los hombres, al mismo tiempo que se evidencia el principio de responsabilidad y libre determinación de aquéllos. Los hermanos que son opuestos, pero que se complementan (el previsor y el mostrenco en este caso), es un tópico que aparece en la tradición mitológica de varias culturas. ${ }^{33}$ Pero, en este caso, Epimeteo no viene únicamente a ser la contraparte de su hermano, sino que, dentro del símbolo del fuego que puede ser benéfico o acarrear desgracias, esta figura se visualiza en los hermanos Titanes, pues ambos pueden simbolizar también la figura del bifronte, es decir, una parte significativa del espíritu humano: una visión hacia el pasado y otra hacia el futuro, que son inseparables. La dualidad formada por Prometeo y Epimeteo es una manera de representar la sabiduría y la torpeza, el progreso y el atraso, como males de la humanidad.

\footnotetext{
${ }^{33}$ Así, por ejemplo, Nopatsis y Akaiyan en las sagas de la India, Anubis y Bata en Egipto, Caín y Abel entre los hebreos, Rómulo y Remo en la cultura romana, etcétera. Cfr. J. F. Bierlein, Parallel Myths, pp. 171 y ss.
} 
En realidad, el texto hesiódico es una verdadera dilatación en torno a los planes de Prometeo, que contraviene el cosmos coronado por Zeus y condena al hombre a vivir del trabajo para alimentar su vientre y el de su compañera. Hesíodo expresa, entonces, una visión pesimista del desarrollo humano, porque la quinta y última raza es la que le toca vivir y, de acuerdo con las descripciones que hace, no resulta nada atractiva la manera en que se vive en comparación con la edad de oro. En efecto, esta última sería una humanidad totalmente masculina, porque no estaba presente la mujer como castigo. ${ }^{34}$ Así, es posible pensar que la quinta raza sea la que todavía estamos viviendo en los tiempos actuales. ${ }^{35}$

Pero cabe resaltar aquí que el género humano se salvó debido a la intervención de Prometeo: él es su salvador pese a las desgracias que le acompañan. Entonces, la figura prometeica puede ser vista como el origen de la quinta raza en el sentido de que la salvó gracias al fuego y no porque la haya creado.

En Hesíodo está presente una voluntad moralizante que se advierte en las distintas sentencias que dirige a los hombres de su tiempo: en principio, la descripción del mundo en que se vive y que es gobernado bajo la tutela de los dioses; luego, su afán personal por establecer la verdadera tradición en torno a los dioses y dar noticia de todas las características que los definen y los distinguen entre sí; pero, sobre todo lo anterior, está el interés del poeta por dejar constancia de que su mundo

\footnotetext{
${ }^{34}$ Cfr. L. Séchan, Le mythe de Prométhée, pp. 25-26, y Jean-Pierre Vernant, op. cit., pp. 22 y ss.

35 "La quinta età, che è la nostra, è quella della generazione del ferro [...] Esiodo non è lieto di vivere nell'età presente, in una generazione i cui individui sono tormentati giorno e notte, pur trovando di tanto in tanto un qualche bene mascolato ai loro mali". Giancarlo Finazzo, La realtà di mondo nella visione cosmogonica esiodea, p. 107. A propósito, Miguel León Portilla, estudioso de las religiones prehispánicas, demuestra que la quinta raza es todavía la actual, de acuerdo con el pensamiento religioso mexica. Cfr. "La religión de los mexicas", en Mercedes de la Garza, Teoría e historia de las religiones, pp. 85 y ss.
} 
presente es el mejor por estar gobernado por Zeus y los dioses olímpicos, de modo que cualquier intento humano por "arreglar" el status quo es infructuoso, "porque todo, en el mundo divino del cielo y de la naturaleza, está organizado, equilibrado y pacificado". ${ }^{36} \mathrm{Si}$ esto es así, el hombre es un ente ajeno a tal organización que desciende desde lo divino.

Con lo anterior, parece que en la tradición que Hesíodo cultivó no hay cabida para una rebelión por parte de los dioses o de los hombres, como la que llevará a cabo Prometeo en las sucesivas versiones del mito. De hecho, Hesíodo establece, de manera secuencial y bajo un orden estricto, la forma en que se desarrolló el traspaso del poder entre los diversos dioses-reyes de la teogonía griega (Urano-Cronos-Zeus), con lo cual elaboró, quizá sin darse cuenta, un poema canónico, hasta cierto punto. No existe el menor asomo de duda en sus palabras, en la urdidumbre de sus poemas épicos. Bajo esta perspectiva, el mito prometeico es de gran relevancia porque significa en el orden hesiódico el punto final de la lucha de Zeus por establecer definitivamente la división entre los mismos dioses olímpicos - la jerarquización definitiva-, pero sobre todo por marcar la línea entre lo divino y lo humano. El hecho de manifestar que Zeus es el poseedor de todos los poderes divinos, y de las cosas futuras relativas al mundo, confirma terminantemente las nuevas reglas del trato entre dioses y hombres.

Hesíodo unifica la moral y la didáctica cuando instruye a los hombres sobre el modo de llevar los asuntos cotidianos y extraordinarios de acuerdo con las leyes propias de la naturaleza. Como campesino que fue, el poeta beocio conoce las costumbres de una sociedad que se encuentra atada a la tradición de la tierra; costumbres que chocan con los procesos socio económicos, como la colonización que se vivía en ese entonces, los cuales hacen que los griegos miren hacia nuevas formas de organización. Esa lucha la vivió Hesíodo en carne

${ }^{36}$ Paola Vianello, op. cit., p. LXVIII. 
propia con el juicio que le incoó su hermano Perses, en el que perdió parte de sus propiedades, heredadas de su padre, por la corrupción de los jueces. ${ }^{37}$

Estos acontecimientos, los sociales y los particulares, tuvieron en Hesíodo una influencia decisiva que se manifiesta en su concepto de justicia: se trata de la justicia de los dioses — de Zeus en especial— que debe conducir a los hombres a la eunomía. Una concepción, adelantada tal vez para su época, de que los derechos sean iguales, según el estatus social, entre los hombres y de que puedan exigirlos en una situación equilibrada y justa. Este pensamiento en su conjunto estaba regido, evidentemente, por el concepto del respeto religioso hacia los dioses y entre los hombres.

Prometeo, como Perses, se atrevió a contravenir el pensamiento justo de Zeus. Si algo debió de entender el hermano de Hesíodo del poema que éste le dedicó, es que la Díke es una especie de herramienta que controla la hybris y, por lo tanto, debía aprender a cultivarla. ${ }^{38}$ De igual manera, Prometeo erró el camino al hacer de su inteligencia una actitud francamente soberbia. Así, el carácter análogo de estos dos personajes sirvió muy bien a Hesíodo para demostrar su tesis sobre la justicia: sólo aquel que se somete a la voluntad del gran Zeus puede alcanzar la efímera felicidad que ha sido otorgada a los mortales. Pero el Cronida estableció una ley para los hombres y dio un castigo —el trabajo — que debe ser acatado por aquellos a quienes les tocó en suerte.

Ahora bien, el paso de un sistema oligárquico y tiránico, bajo el que vivió Hesíodo, a la democracia influye sustancialmente en la forma en que se analiza la figura prometeica. De ser el causante de las desgracias del hombre, la Ilustración griega de los siglos v y IV observó en el Titán un redentor de los hombres, según se puede colegir del Prometeo encadena-

\footnotetext{
${ }^{37}$ Hes., Erga, v. 213.

${ }^{38}$ Jean-Pierre Vernant, op. cit., p. 66.
} 
do atribuido a Esquilo ${ }^{39}$ y, además, advirtió el vínculo entre los efímeros y Zeus mediante el concepto de política, si en este último caso atendemos el mito del Titán que Platón pone en labios de Protágoras en el diálogo homónimo.

La cuestión que trata Prometeo encadenado se refiere clara y específicamente al castigo del Titán, y más puntualmente a la forma en que éste es encadenado a la montaña escita y los males que sufre a partir de este castigo: la vergüenza de que sus enemigos lo vean como un ser vencido, el sufrimiento físico, pero sobre todo substancial, de que su hígado sea devorado por el águila de Zeus y el hecho de que, al final, sea enviado al inframundo. La fuente directa que influyó en el autor de Prometeo encadenado fue la poesía hesiódica.

Entre los poemas épicos de Hesíodo y la pieza trágica adjudicada a Esquilo en cuanto al mito de Prometeo, se puede observar una continuidad en la línea narrativa: Hesíodo pone énfasis en el éthos ankylométes del Titán y los efectos que esta manera de ser provoca entre los dioses y directamente en perjuicio de los hombres, los males, entre los cuales destaca el trabajo necesario para subsistir, la lejanía cada vez más marcada entre la justicia divina (Zeus) y el proceder de los hombres. En Esquilo todo esto se pierde porque constituye un suplemento inorgánico, según el fin propuesto en su tragedia: la libertad. Por lo tanto, el mito de Pandora y el de las cinco razas humanas son materiales anulados temáticamente en la tragedia esquilea. El asunto del Prometeo encadenado inicia, por así decirlo, in media res.

\footnotetext{
${ }^{39}$ Esquilo, el supuesto autor de esta tragedia, vivió entre la caída de la tiranía y el nacimiento de la democracia. Este hecho definió algunas de sus ideas políticas y, en gran medida, la creación de sus tragedias, y específicamente este aspecto parece evidenciarse en el Prometeo encadenado, como se tratará de demostrar más adelante. En efecto, a pesar de que Esquilo no estuvo comprometido de manera directa con las actividades políticas, no por ello deja de reflexionar y opinar sobre el asunto en las tragedias que se le atribuyen. A decir de Vidal-Naquet, lo único cierto a este respecto es que Esquilo deja a sus lectores en la incertidumbre política. Cfr. Pierre Vidal-Naquet, El espejo roto, p. 24.
} 
La tesis central del pensamiento político que se puede percibir en esta tragedia es que Zeus es presentado como un tirano, una deidad alejada de la justicia y que gobernaba, entonces, con un carácter prepotente y voluble. Se puede afirmar que el Cronida esquileo es la antítesis del descrito por Hesíodo. ${ }^{40}$ Zeus representa y es en sí mismo el poder absoluto, lo cual quiere decir que nadie se puede oponer a sus designios, ni los hombres ni los dioses; esto lleva a pensar que en sus consideraciones Zeus no le toma parecer a nadie y tampoco rinde cuentas de sus actos. Esta observación concuerda con la imagen del tirano descrita en Los Persas, tragedia en la que se aprecia la oposición entre el despotismo de la tiranía persa frente a la organización democrática de Atenas: el punto nodal que marca esta diferencia es la hybris del tirano que, como en el caso de Zeus, desdeña a la polis. ${ }^{41}$

La idea anterior se apoya en el hecho de que el desarrollo ideológico del Prometeo encadenado refleja la evolución política y religiosa del pueblo griego: de las ideas mitológicas y religiosas plasmadas por Hesíodo a las nuevas reflexiones que surgen a propósito de la evolución de la democracia y de los planteamientos de la sofística, lo cual se advierte en la imagen de Zeus descrito como un tirano, en un sentido execrable, y en la imagen del Prometeo rebelde, que es la voz disidente en el Coro que alaba o se somete al nuevo orden impuesto por el Cronida. Como este dios no interviene de modo directo en la representación de Prometeo encadenado, el tópico de la injusticia expuesto y argumentado por Prometeo y, de modo colateral, por Hefesto, Ío y el Coro, delimita una visión adversa a Zeus.

Si pensamos en el marco del relativismo propuesto por Protágoras en el sentido de que el hombre piensa a sus dioses como la figura y la razón de sí mismo, resulta, entonces,

\footnotetext{
${ }^{40}$ Esq., $P$. , vv. 11 y ss.

${ }^{41}$ Esq., Los Persas, v. 213. Cfr. F. Sartori, "Echi politici ne I Persiani di Eschilo", en Atti Ist. Filologia, 128, 1969-1970, pp. 771-797.
} 
bastante afortunado el paralelismo que establece Solmsen entre la creación histórica del Areópago como institución encargada de administrar la justicia y el nuevo cosmos que aparece con el advenimiento de Zeus como patrono de los dioses y de los hombres. El Areópago nace como institución social por la necesidad de encontrar un mecanismo regulador de la justicia en las poleis griegas, y es producto también de la confrontación entre la oligarquía y la democracia. Esta confrontación es similar a la que sostienen Zeus y Prometeo en el drama atribuido a Esquilo. En efecto, el Titán llama tirano a Zeus con toda la connotación ideológica que tal palabra podía tener en la recepción del público ateniense y, además, Prometeo es identificado por los dioses que coinciden con Zeus (Cratos, Bía, Hermes) como rebelde contra el sistema vigente. Se trata, pues, de una tragedia que expone uno de los puntos medulares más sobresalientes en el cosmos griego: la tensión del sistema de organización religiosa — por extensión, política- que sustituye a otro modelo de pensamiento. La tensión entre la tiranía (oligarquía) y la democracia es el reflejo de la lucha que sostiene Zeus contra sus enemigos (Atlas, Tifón, Prometeo, etcétera) con el fin de establecer su poder. Los hombres piensan a sus dioses como un espejo de sus dilemas. ${ }^{42}$

Es importante señalar también que Zeus recién empieza a gobernar, según el momento escénico en que se desarrolla la pieza trágica, y que seguramente el castigo de Prometeo es una de las primeras acciones que el rey de los dioses lleva a cabo y, como dice Hefesto, "es inexorable el corazón de Zeus y riguroso todo el que empieza a ejercer el poder". ${ }^{43}$ Más adelante el Coro de las Oceánides confirma esta apreciación:

\footnotetext{
${ }^{42}$ Se puede afirmar que durante la democracia era usual el topos sobre la execración de la tiranía; por ejemplo, Sof., Ant., vv. 506 y 507: "En efecto, a la tiranía le va bien en otras muchas cosas, y sobre todo le es posible obrar y decir lo que quiere". Cfr. también Eurípides, Ión, vv. 261-263.

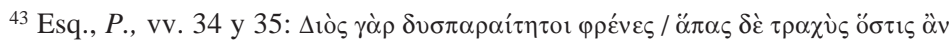

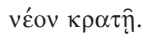


"Nuevos timoneles, en efecto, / dominan el Olimpo, y ya con recientes decretos / ejerce Zeus el poder inicuamente, / y aniquila ahora a los colosos de antaño". ${ }^{44}$

Así, un elemento sobresaliente en la tragedia es la sucesión entre las distintas generaciones de dioses que han gobernado: Urano-Cronos-Zeus; ${ }^{45}$ este esquema de sucesión ya se encuentra establecido en los poemas hesiódicos y le sirve a Esquilo de fondo para la tragedia. En la sucesión divina, el mismo Prometeo ha participado en la lucha para derrocar a Cronos al ponerse del lado de Zeus, siguiendo el consejo de Gea, su madre. ${ }^{46}$ Ésta es una nueva interpretación que hace Esquilo acerca de la actitud de Prometeo en el marco de la Titanomaquia, hecho que compromete a Zeus de cierto modo con esta deidad. ${ }^{47} \mathrm{Y}$, no obstante que Zeus pudo vencer a sus enemigos con la ayuda del Titán, lo traicionó, como puede observarse en el castigo que le aplicó por robarse el fuego.

Sin embargo, hay una destacada diferencia entre la versión de Hesíodo y la de Esquilo en torno a la sucesión divina: para el poeta beocio el arribo de Zeus al poder significa el establecimiento de un gobierno de justicia, de modo que con él concluyen los parricidios - y los deicidios-. Por el contrario, en Prometeo encadenado se retoma la tradición mítica donde se señala que el hijo de Zeus y Metis sería el causante de que el Cronida perdiera el poder. ${ }^{48}$ Es en esta línea del castigo y

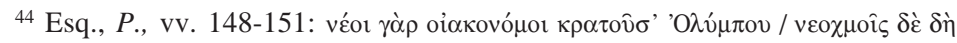

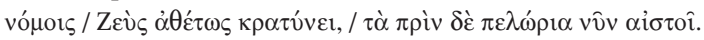

${ }^{45}$ Cfr. D. J. Conacher, Aeschylus' Prometheus bound, p. 7.

${ }^{46}$ Esq., $P$., vv. 200-225. Hesíodo dice que Prometeo es hijo de Climene, lo que hace inferir que se trataría de un ser inferior jerárquicamente frente a Zeus; mientras que Esquilo expresa que es hijo de Gea, es decir, primo de Zeus. Cfr. también F. Solmsen, op. cit., pp. 126 y 131.

${ }^{47}$ En la parte referente a la Titanomaquia, Hesíodo menciona que Gea ayudó a los dioses olímpicos junto con Estigia y su descendencia, además de los Hecatónquires. Cfr. Theog., vv. 617 y ss.

${ }^{48}$ El tópico del casamiento de Zeus con Metis tal vez fue tomado por Esquilo de la Ístmica VIII de Píndaro.
} 
de la venganza en la que Esquilo sitúa el devenir de los dioses y, específicamente, la historia de Prometeo, pues este Titán conoce quién es el personaje que habría de destronar a Zeus.

La traición "es un mal de la tiranía, no confiar en los propios amigos", según las palabras de Prometeo. ${ }^{49}$ En este pasaje queda en duda la justicia que Zeus pretende imponer en el marco de su poder recién obtenido. Pero, por encima todavía de la traición de Zeus, se encuentra el error de no haber tomado en cuenta a los hombres en la repartición de los derechos y obligaciones. Al contrario, el Cronida quiso destruirlos y crear una raza nueva y el único que se opuso a ello fue Prometeo. ${ }^{50}$ En este pasaje no queda clara la sucesión de la genealogía humana. Tal parece que Prometeo trató de salvar a la raza que él mismo había originado, mientras que, de acuerdo con Hesíodo, se puede conjeturar que la raza que pretende salvar el Titán es la que el mismo Zeus ya había creado; lo anterior está enmarcado en la parte del relato hesiódico que habla del sacrificio de Mecona. Este sacrificio fue para sellar el acuerdo entre los dioses, en particular Zeus, y los hombres; de ahí que se infiera también que, como ya se mencionó, éstos conocían el fuego, y el fuego nuevo que les fue entregado por Prometeo es aquel que Zeus arrebató a los hombres para que perecieran.

Así pues, sin el fuego, el ser humano quedaría reducido a su estado primitivo, a la condición de un animal o, incluso, conducido a la misma muerte, mientras que con su uso el hombre conocería todas las técnicas posibles; de ahí el elogio a este elemento cuando se dice que es "maestro de todas las artes". ${ }^{51}$ De hecho, la idea de un Prometeo liberador aparece por vez

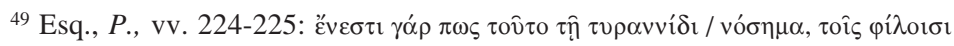
$\mu \grave{\eta} \pi \varepsilon \pi \mathrm{ot} \theta \dot{\varepsilon} v \alpha 1$.

${ }^{50}$ Esq., P., vv. 300-336.

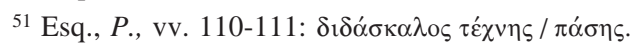


primera con la tragedia de Esquilo. Prometeo ama a los hombres, y por esta causa se enfrenta al dios tirano. La filantropía divina parece tener aquí su nacimiento literario o, al menos, una de sus fuentes más antiguas.

Prometeo, en este sentido, es el más señalado de los héroes culturales dentro de la tradición mitológica de la Grecia antigua, y tal vez de la civilización occidental. Su naturaleza filantrópica forja su papel de mediador entre los terrenos divino y humano. El héroe cultural tiene entre sus características principales la de establecer una tensión entre los dioses y los hombres. Quizá allí reside la esencia de la tragedia prometeica: tomar la decisión de estar en paz con Zeus y con los demás dioses o ayudar a los mortales en sus desgracias.

La tensión mencionada ya existía en la narración hesiódica, pues el Titán pretendía, según el poeta beocio, que los seres humanos fueran semejantes a los dioses al darles el fuego. Esquilo, en comparación con Hesíodo, fue más allá en su versión trágica del mito de Prometeo: la ayuda que el Titán proporciona a los hombres lo convierte prácticamente en su creador, pues con el fuego los transformó en humanos, es decir, les quitó su naturaleza bárbara. Prometeo, visto como la imagen de un dios creador, abrió todas las posibilidades físicas e intelectuales en el hombre de manera que su proceder es superior al del mismo Zeus ${ }^{52}$ este dios no hizo lo que llevó a cabo el Titán por los seres humanos. Aquí se explica la visión contraria en cuanto a la inteligencia entre Hesíodo y Esquilo, si se toma en cuenta el papel que Prometeo desempeñó en la historia de la humanidad.

Si Hesíodo es agudo en el tema del engaño, de la mente tortuosa del Titán, la versión trágica redime, hasta cierto punto, el proceder de Prometeo por haber entregado a los hombres no sólo el fuego, sino su propio sufrimiento:

\footnotetext{
${ }^{52}$ Esq., $P .$, vv. 506 y ss.
} 
Mas ni silenciar ni no silenciar tales suertes me es posible, pues a los mortales una ofrenda entregué y por ello ahora estoy uncido a estos suplicios funestos. En el hueco de un carrizo capturé del fuego el manantial furtivo, como maestro de todo arte, $\mathrm{y}$, para los mortales, como gran recurso ha surgido.

Los pesares de tales faltas expío,

a campo raso, atado con cadenas. ${ }^{53}$

En la versión que Esquilo ofrece sobre el símbolo del fuego como elemento esencial de la civilización, resulta evidente la diferencia que existe en relación con el mismo punto tratado por Hesíodo. Para el poeta beocio, el progreso se encuentra en el respeto que el hombre debe observar de la justicia; sólo por el recto camino de lo justo y lo equilibrado, la humanidad florecería de modo adecuado. ${ }^{54}$ En cambio, según Prometeo encadenado el progreso se halla en la medida en que los hombres alcanzan su libertad. El hombre supera sus limitaciones naturales con el uso del fuego al tener la posibilidad de desarrollar todas las artes, las cuales, además, le fueron enseñadas por el mismo Prometeo. ${ }^{55}$ Como héroe cultural, el Titán es una especie de progenitor de la raza humana, un deus-homo faber. El fuego, como símbolo, es la encarnación visible del

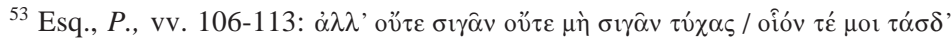

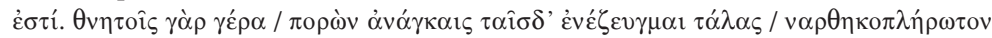

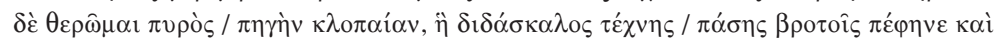

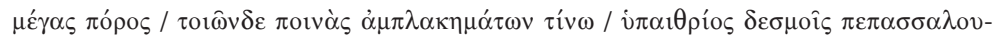

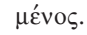

${ }^{54}$ Giancarlo Finazzo, op. cit., p. 120: "Ma il fatto stesso che ogni azione compiuta senza rispetto della giusta misura, sia vinta dalla giustizia quando abbia raggiunto il suo compimento, ci fa intuire che l'uomo, seguendo la retta via, ne avrà naturalmente del benefici. Apprendiamo infatti che seguendo la giustizia le città e le popolazioni fioriranno".

${ }^{55}$ W. Jaeger encuentra cierta similitud entre la filosofía de Parménides sobre la revelación de la verdad en el hombre y la propuesta de Esquilo sobre un

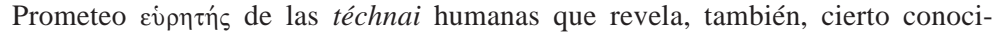
miento a los hombres. La teología de los primeros filósofos griegos, pp. 98-100.
} 
progreso humano, y en su momento tal vez representó incluso el deseo de trascender lo estrictamente humano, ${ }^{56}$ pero sin tener como meta el modelo de dios. Sin embargo, hay que considerar también que el fuego es una especie de concesión divina que mantiene una relación estrecha entre los hombres y los dioses. ${ }^{57}$ El fuego los mantiene atados, a pesar de sus diferencias.

De acuerdo con los vv. 442-506 de Prometeo encadenado, gracias al Titán, la humanidad tomó conciencia y aprendió a dominar sus pasiones; esta apreciación marca una distancia notable entre el hombre y la bestia. La sabiduría trajo beneficios: el hombre construyó sus casas y salió de las cuevas, donde vivían como hormigas que no conocían el sol; reconoció el cambio de las estaciones al aprender a leer las estrellas; conoció el número y la letra; desarrolló la mántica en sus diversos medios y practicó la ganadería y la marinería. En fin, "en pocas palabras, sábete todo en breve: / todas las artes para los mortales provienen de Prometeo". 58

En el conjunto de estos versos, el Titán expone la idea del progreso en un sentido positivo. En efecto, las características del hombre en su estado natural son descritas por la oposición de los dones que Prometeo dio a los hombres a través del fuego. Guthrie a este respecto escribió que

se extendiese o no un manto religioso sobre la narración, mediante alguna alusión más bien mecánica a Prometeo o algún otro poder sobrehumano que hubiese concedido a los hombres el ingenio para mejorar sus vidas, fue por la dura necesidad y

\footnotetext{
${ }^{56}$ Cfr. L. Séchan, Le mythe de Prométhée, pp. 14-15.

${ }^{57}$ Hay que observar que Esquilo sólo toma el tópico del fuego en la disputa entre Zeus y Prometeo, mientras que en la versión hesiódica éste es el centro de la segunda afrenta que el Titán comete contra el Cronida. Esquilo soslaya el asunto del sacrificio en Mecona para el desarrollo del tema de la libertad.

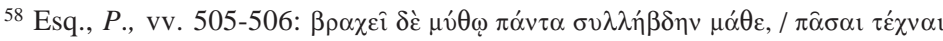

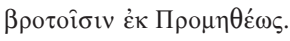


por la inteligencia connatural por lo que el progreso se llevó a cabo. ${ }^{59}$

En el imaginario mitológico, esa necesidad y esa inteligencia connatural recibieron un nombre y un culto divino en la imagen de Prometeo.

Así pues, el Titán concedió todos los beneficios señalados con la donación del fuego a los hombres, acción realizada a espaldas de los dioses, en especial de Zeus y de Hefesto, pues lo roba de la fragua de éste. El fuego entregado de manera ilícita se convierte en signo de rivalidad entre el mundo divino y el humano. Como héroe cultural, Prometeo separa ambos territorios con el robo y cesión del fuego a los hombres: el fuego se convierte, así, en la frontera desde la cual el hombre divisa a los dioses. Sin embargo, de manera paradójica, al mismo tiempo se asegura el vínculo permanente entre los mortales y las deidades, pues el fuego aun en las manos de la raza humana conserva su carácter sagrado. ${ }^{60}$

Ahora bien, más que los beneficios concretos del fuego, Prometeo trató de evitar que el ser humano tuviera ante sí un final fatal (la muerte), al fundar en él la vana esperanza. ${ }^{61} \mathrm{El}$ hombre, siguiendo su afán de progreso, camina con la esperanza de evitar la muerte. La tradición que recoge Hesíodo en torno al hecho de que con el fuego los hombres pueden llegar a ser semejantes a los dioses, seguramente se refiere a la inmortalidad tan deseada por el género humano. ¿Es ésta la vana esperanza que Prometeo donó a los hombres? Recordemos que en la versión hesiódica, el mito de Pandora es la continuación del relato de las cinco razas humanas, y que el centro de ambos lo constituye, sin duda, el mito de Prometeo.

\footnotetext{
${ }^{59}$ W. K. C. Guthrie, Historia de la filosofía griega, t. II, p. 480. Cfr. L. Edelstein, The Idea of the Progress in the Classical Antiquity, pp. 21-26.

${ }^{60}$ Cfr. Th. G. Rosenmeyer, The Masks of Tragedy, p. 64.

${ }^{61}$ Esq., $P .$, vv. 248 y ss.
} 
Cuando la jarra que llevaba consigo Pandora es abierta, los males se esparcen por el mundo para desgracia del género humano; sólo la esperanza quedó atrapada en el borde. Ésta venía con los males y debe entenderse que es uno más de ellos. Como lo ha analizado Paola Vianello, ${ }^{62}$ la esperanza es un término doble, positivo y negativo: la vana esperanza que sembró Prometeo en los hombres es un mal, y dentro de los males es de los menores porque le ayuda a sobrellevar su vida. Quizá el progreso en la tragedia esquilea sea justamente percibido como un espejismo de la esperanza.

Si lo anterior es así, la vida civilizada fue fundada sobre la obcecación de Zeus y de Prometeo. El hombre ve el futuro como una simple ilusión que nunca alcanzará: la inmortalidad, y se consuela con sus novedades técnicas que le ayudan a conducir su vida con cierto desahogo. En este sentido, uno de los aspectos de la tragedia humana es que el hombre civilizado resulta impotente, de cualquier modo, ante los designios divinos. Pero, además de la técnica, la humanidad cuenta con la rebeldía que se expresa en la libertad que posee para decidir, tal como lo demuestra la experiencia de Prometeo. Esta libertad es desconocida también por Zeus, en tanto que bajo el esquema en que rige "su cosmos" no cabe la posibilidad de la libertad moral.

Según Gadamer, ${ }^{63}$ las culturas sólo florecen cuando su porvenir se ve rodeado de mitos; cuando hay carencia de éstos, los pueblos muestran agotamiento, su espíritu se enferma. De acuerdo con esta idea, el progreso está indefectiblemente unido con la manifestación de los mitos. A nuestro juicio, el mito de Prometeo reúne los tópicos referentes al progreso y a la

\footnotetext{
${ }^{62}$ Paola Vianello, "Introducción”, en Hes., Los trabajos y los días, pp. XXXV y ss.: "La Esperanza, pues es un mal; sin embargo, ya que Zeus a través de Pandora impide que salga y vague entre los hombres, ella no adquiere el carácter de mal inevitable y, a diferencia de otros males liberados, puede ser controlada por la humanidad".

${ }^{63}$ Mito y razón, p. 16.
} 
tradición, al atraso y al caos. Es en la dialéctica de tales extremos de donde surge el espíritu prometeico que revela a la humanidad su grandeza y su miseria, siendo aquélla hija de la inconformidad por ser sólo hombres y por deseñar, al mismo tiempo, la posibilidad de ser dioses.

\section{BIBLIOHEMEROGRAFÍA}

\section{Fuentes}

Aeschylus, Prometheus Bound, ed. Mark Griffith, Cambridge, Cambridge University Press, 1988.

—, Suppliant Maidens, Persians, Prometheus, Seven against Thebes, ed. y trad. Herbert Weir Smith, Cambridge, Harvard University Press, 2001.

Hesíodo, Los trabajos y los días, est. general, intr., vrs. rítmica y nts. Paola Vianello de Córdova, México, Universidad Nacional Autónoma de México (Bibliotheca Scriptorum Graecorum et Romanorum Mexicana), 1986 (1979).

-, Teogonía, est. general, intr., vrs. rítmica y nts. Paola Vianello de Córdova, México, Universidad Nacional Autónoma de México (Bibliotheca Scriptorum Graecorum et Romanorum Mexicana), 1986.

Homère, Iliade, t. II, ed. y trad. Paul Mazon, Paris, "Les Belles Lettres", 1972.

Lucian, Opera, ed. M. D. MacLeod, Oxford, Oxford University Press, 1972.

Pindare, Olympiques, ed. y trad. Aimé Puech, Paris, "Les Belles Lettres", 1970.

Sofocle, Antigone, Edipo Re, Edipo a Colono, intr., trad. y nts. Franco Ferrari, Milano, BUR, 2004.

\section{Bibliohemerografía general}

Bierlein, Paralell myths, New York, Ballantine Wellspring, 1994.

Camus, Albert, L’homme révolté, Paris, Gallimard, 1999 (1951).

Conacher, J. D., Aeschylus' Prometheus bound: a Literary Commentary, Toronto, University of Toronto Press, 1980. 
Durand, J. L. Véase Gentili.

Edelstein, L., The Idea of the Progress in the Classical Antiquity, Baltimore, Johns Hopkins University Press, 1967.

FInAzzo, Giancarlo, La realtá di mondo nella visione cosmogonica esiodea, Roma, Edizioni dell'Ateneo, 1971.

Frazer, J. G., La rama dorada, México, Fondo de Cultura Económica, 1992 (1951).

GadAmer, Hans-Georg, Mito y razón, Barcelona, Paidós, 1997.

Garza, Mercedes de la, y Ma. del Carmen VAlverde (coords.), Teoría e historia de las religiones, México, Facultad de Filosofía y Letras, Universidad Nacional Autónoma de México, 1998.

Gentili, Bruno, Il mito greco, Roma, Edizioni dell'Ateneo \& Bizarri, 1973.

Guthrie, W. K. C., Historia de la filosofía griega, t. II, Madrid, Gredos, 1984.

JAEGER, Werner, La teología de los primeros filósofos griegos, México, Fondo de Cultura Económica, 1998 (1947).

KerÉnyI, Carl, Prometheus. Archetypal Image of Human Existence, Princeton, Princeton University Press, 1997.

McCall, Marsh H., Aeschylus. A Collection of Critical Essays, New Jersey, Prentice Hall, 1972.

Rosenmeyer, T. G., The Masks of Tragedy, Austin, Austin University Press, 1963.

SAÏD, Suzanne, Sophiste et tyran ou le problème du Prométhée enchaîné, Paris, Klincksieck, 1985.

SARtori, F., "Echi politici ne I Persiani di Eschilo", en Atti Inst. Filologia, 128, 1969-1970, pp. 771-797.

SÉchan, Louis, Le mythe de Prométhée, Paris, Presses Universitaires de France, 1951.

Solmsen, Friedrich, Hesiod and Aeschylus, New York, Cornell University Press, 1995 (1949).

Thomson, George. Véase McCall.

Vernant, Jean-Pierre, Mito y pensamiento en la Grecia antigua, Barcelona, Ariel, 2001 (1973).

VIDAl-NAQUet, Pierre, El espejo roto. Tragedia y política en la Grecia antigua, Madrid, Abada, 2004 (2001). 
